\title{
A sea spray generation function for fetch-limited conditions
}

\author{
J. Piazzola ${ }^{1}$, P. Forget ${ }^{2}$, and S. Despiau ${ }^{1}$ \\ ${ }^{1}$ LEPI, University of Toulon-Var, France \\ ${ }^{2}$ LSEET, University of Toulon-Var, France
}

Received: 23 April 2001 - Revised: 20 July 2001 - Accepted: 20 July 2001

\begin{abstract}
This paper presents a sea spray generation function for aerosols produced by bubbles bursting that accounts for the effects of fetch. This is achieved by introducing a fetch-dependent model for the whitecap fraction, which is valid for fetch-limited conditions, i.e. steady-state conditions of the wave field in the whitecap droplet flux derived by Monahan et al. (1986). The aerosol generation fluxes calculated by this method show an enhancement of the aerosol production with increasing fetch. However, the predicted generation fluxes are lower than those calculated by using the classical model for the whitecap fraction proposed by Monahan and O'Muircheartaigh (1980). The results are then compared to aerosol size distributions measured in a Mediterranean coastal site at various fetch lengths. The data confirm the role of fetch, through its influence on marine aerosol generation and subsequent particle dispersion. The aerosol size distributions are divided into "fine" and "coarse" fractions. Submicrometer particles decrease in concentration at larger fetch, while the concentrations of super micron aerosols increase with increasing fetch.
\end{abstract}

Key words. Atmospheric composition and structure (aerosols and particles) Meteorology and atmospheric dynamics (waves and ties) Oceanography: physical (air-sea interactions)

\section{Introduction}

Aerosols have a significant influence on the global climate through their ability to scatter and absorb radiation (Charlson et al., 1992). In addition, they are important to our life conditions and health as a direct contribution to the atmospheric pollution regardless of whether they are of anthropogenic origin (e.g. urban emission, factory dust) or indirect origin when they are created from natural sources since they transport pollutants and bacteria. Aerosol particles mechanically produced by the interaction between wind and waves

Correspondence to: J. Piazzola (piazzola@isitv.univ-tln.fr) constitute a major component of the natural aerosol (Andreae, 1995). When the wind speed increases, the energy of the wind becomes too much to be absorbed by the waves, which break to dissipate the excess energy. When the ocean wave breaks, air entrained into the water breaks up into bubbles, which may be transported to depths of several meters. When the bubbles rise and reach the surface, they burst and produce two kinds of droplets: film drops and jet drops. Detailed studies of the production of jet and film drops were made by observing the artificial burst of a single bubble (e.g. Blanchard, 1963; Resch and Afeti, 1992). High wind speed periods $(V>10 \mathrm{~m} / \mathrm{s})$ are associated with a direct production of large aerosols extracted by the airflow at the crest of the waves (Monahan et al., 1983). The aerosol production is proportional to the whitecap fraction, commonly denoted as $W$. According to Monahan et al. (1986), the number of spray droplets of radius $r$ produced per square meter of surface, per second, per micrometer increment in $r$ is:

$d F / d r=W \tau^{-1} d E / d r$

where $\tau$ is the time constant characterizing the exponential whitecap decay (with typically $\tau=3.53 \mathrm{~s}$ ) and $d E / d r$ is the number of droplets per increment droplet radius produced during the decay of a unit area of whitecap (expressed in $\left.\mathrm{m}^{-2} \mu \mathrm{m}^{-1}\right)$.

Equation (1) implies that the aerosol concentration increases with the whitecap fraction $W$. The knowledge of the whitecap fraction $W$ is then of great importance to predict the aerosol concentrations in the marine atmospheric boundary layer. In earlier studies, the whitecap fraction was related to the wind speed (in $\mathrm{ms}^{-1}$ ), generally referred to as a $10 \mathrm{~m}$ height (Monahan, 1971). The most commonly used expression is (Monahan and O'Muircheartaigh, 1980):

$W(\%)=3.84 \cdot 10^{-4} U^{3.41}$

In the coastal zone, however, one can expect that the whitecap fraction $W$, and thus the sea surface-generated particle concentration differ from open ocean conditions due to, for example, wave-current interactions, bottom influence or 
shore processes. In addition, the whitecap cover depends on the wind's trajectory over water, i.e. the fetch, since wave breaking is different for a fully developed sea compared to growing wave field periods (Monahan and Monahan, 1986; Monahan and Woolf, 1989). The knowledge of the variation of whitecap fraction with respect to the fetch is then required to estimate the marine component of the aerosol concentration in coastal zones.

The purpose of this paper is to present a spray generation function that accounts for the effects of fetch. To this end, a fetch-dependent model for the whitecap fraction is established using an expression proposed by Toba and Koga (1986) combined with a wave parametric formulation. This model, valid for fetch-limited conditions, i.e. steadystate conditions of the wave field, is then introduced in the whitecap droplet flux derived by Monahan et al. (1986). This fetch-dependent spray generation function is valid for indirect production through bubble bursting processes. Finally, the generation flux calculations are compared to experimental aerosol size distributions measured at different fetch lengths made in the Mediterranean coastal zone.

\section{Fetch dependent models for the whitecap fraction}

It is well recognized that the wind stress is the key parameter of air-sea interaction processes. The wind stress can be alternatively modeled in terms of the wind drag coefficient $C_{D}$, or in terms of $z_{o}$, the so-called surface roughness length, which can be defined as the lowest altitude of the logarithmic wind profile above the mean sea level. In neutral conditions, we have

$U_{z}=\frac{u_{*}}{k} \ln \left(z / z_{o}\right)$

where $k$ is the von Karman constant $(\approx 0.40), u_{*}$ is the wind friction velocity, and $U_{z}$ is the wind speed at $z \mathrm{~m}$ height. Under near-neutral conditions, the wind drag coefficient can then be written as

$C_{D}=\frac{u_{*}^{2}}{U_{z}^{2}}=\left(\frac{k}{\ln \left(z / z_{o}\right)}\right)^{2}$.

Since the wind stress includes atmospheric stability and turbulence effects, it is recommended to express the whitecap fraction $W$ as a function of the friction velocity $u_{*}$. As suggested by Wu (1979) and confirmed by Monahan (1988), the whitecap cover can be related to the cube of the wind friction velocity. In its recent form, the whitecap fraction $W$ (hereinafter $W_{w}$ ) proposed by $\mathrm{Wu}(1988)$ on the basis of a data set from BOMEX, JASIN, STREX and MIZEX can be written as

$W_{w}(\%)=20 u_{*}^{3}$.

Since parameters characterizing the air-sea interaction processes, such as $u_{*}$ (in $\mathrm{ms}^{-1}$ ), depend on the sea state (Hsu, 1986), Eq. (5) implicitly assumes a dependence of $W$ on the wave field. As the wave field varies with fetch, Eq. (5) then represents a first fetch-dependent whitecap model.
On the basis of a simulation tank data and dimensional arguments, Toba and Koga (1986) proposed an alternative expression for the whitecap fraction:

$W_{T K}(\%)=8.9 \cdot 10^{-5}\left(\frac{u_{*}^{2}}{2 \pi v f_{p}}\right)$

where $v$ is the air viscosity. This formulation not only implicitly relates the breaking process to the sea state through $u_{*}$ (in $\mathrm{ms}^{-1}$ ), as in Eq. (5), but it also involves an explicit dependence through the wave peak frequency, $f_{p}$. The relationship between the two formulations is then

$W_{w}=K f_{p} u_{*} \cdot W_{T K}$

where

$K=\frac{2 \cdot 20 \pi v}{8.9 \times 10^{-5}}$ is about 20.

When the wave field is fully developed, we can assume that $f_{p}=0.13 g / U_{10}$ (Komen et al., 1984), where $U_{10}$ is the wind speed at a ten meters height and $g$ is the acceleration of the gravity. During such conditions, for a given wind speed, the wind drag coefficient is constant. In particular, for a fixed wind speed lower than $10 \mathrm{~m} / \mathrm{s}$, Large and Pond (1982) suggest a simple constant $C_{D}$ of $1.1410^{-3}$. Thus, the peak frequency of Komen et al. (1984) introduced in Eq. (6) leads to:

$W(\%) \approx 23 u_{*}^{3}$

We note that this expression shows a remarkable agreement with the one reported in Eq. (5). For this reason, we suggest that the two formulations for the whitecap fraction reported in Eq. (5) and Eq. (6) are equivalent for fully developed seas.

However, for short fetches, we must take into account the wind wave growth with the fetch length. A variety of models exist in the literature relating $z_{o}$ to the sea state characteristics (e.g. Hsu, 1974; Huang et al., 1986; Geernaert, 1990; Maat et al., 1991; Donelan et al., 1993; Johnson et al., 1998). We will use in the present paper, the parameterization of $z_{o}$ in terms of the significant wave height, $H_{s}$, and the wave age proposed by Donelan et al. (1993):

$z_{o}=1.6810^{-4} H_{S}\left(U_{10} / C_{p}\right)^{2.6}$

In deep water, the wave velocity $C_{p}$ can be related to the wave peak frequency as

$C_{p}=\frac{g}{2 \pi f_{p}}$

For wave field predictions, the parametric models (Hasselman et al., 1973) make assumptions about the spectral shape in order to reduce the problem of the growth of wind waves to a few dimensionless parameters. Under fetch-limited conditions, we assume that the wind has blown constantly long enough for wave heights at the end of the fetch to reach equilibrium. Such a constraint can be expressed by (Carter, 1982):

$D>1.167 X^{0.7} / U^{0.4}$ 
where $D$ is the duration of the wind (in hr), $X$ is the fetch length, expressed in $\mathrm{km}$ in Carter (1982), and $U$ is the wind speed (in $\mathrm{m} / \mathrm{s}$ ). For example, for a wind speed of $10 \mathrm{~m} / \mathrm{s}$, Eq. (11) predicts that the equilibrium is reached in 1 hour for a $3-\mathrm{km}$ fetch and after 3 hours for a $22-\mathrm{km}$ fetch. This is generally well satisfied by the northwest winds in the study area.

Expressions relating $f_{p}$ and $H_{s}$ to the fetch length $X$ (in metres) and the wind speed (in $\mathrm{ms}^{-1}$ ) at $10 \mathrm{~m}$ above the sea level are numerous (e.g. Hasselmann et al., 1973; Mitsuyasu et al., 1980; Kahma, 1981; Donelan et al., 1985). These relationships have the form

$$
\begin{aligned}
& f_{p}=\frac{\alpha_{3} g}{U_{10}} \xi^{\alpha_{4}} \\
& H_{s}=\frac{\alpha_{5} U_{10}^{2}}{g} \xi^{\alpha_{6}}
\end{aligned}
$$

where $\xi$ is the non-dimensional fetch, as expressed by $\frac{g X}{U_{10}^{2}}$ and with, typically, $\alpha_{3}=3.5, \alpha_{4}=-0.33, \alpha_{5}=1.6 \cdot 10^{-3}$, $\alpha_{6}=0.5$ (Hasselmann et al., 1973; Hsu, 1986).

On the basis of Eqs. (4), (9), (12) and (13), the formulation for the drag coefficient in neutral stratification conditions is given by

$$
C_{D}=\frac{k^{2}}{\left[12.505+0.358 \ln (X)-2.716 \ln \left(U_{10}\right)\right]^{2}} .
$$

Equation (14) leads to a wind drag coefficient which decreases with increasing fetch. This is in accordance with most of the air-sea interaction studies (see, recently, Vickers and Mahrt, 1997). By combining Eq. (6) and Eq. (12), we obtain a new formulation for the whitecap fraction specifically adapted to short fetch lengths, which is expressed by:

$W(\%)=0.06 C_{D} U_{10}^{7 / 3} X^{0.33}$

where $C_{D}$ is given by Eq. (14). It should be noted that the expression can be directly written as a function of $u_{*}$, by using the expression similar to Eq. (12), but $u_{*}$ dependant (see, for example, Mitsuyasu et al., 1980). This leads to

$W(\%)=0.206 u_{*}^{7 / 3} X^{0.33}$.

A comparison between the whitecap fraction models reported in Eq. (2), Eq. (5) and Eq. (15), using the wind drag coefficient reported in Eq. (14), is reported in Fig. 1 for a wind speed of $10 \mathrm{~m} / \mathrm{s}$. We can see that the models disagree dramatically at short fetches. In particular, the latter ones show a contrary behaviour with respect to the fetch. As shown in Fig. 1, as the fetch increases from 1 to $50 \mathrm{~km}$, Eq. (15) predicts about a 4 to 2 difference factor in the whitecap fraction compared to the models reported in Eq. (2) and Eq. (5). For a steady-state wave field, the whitecap percentage predicted by Eq. (15) for short fetches seems to be more realistic than that derived using Eq. (5). In particular, recent data collected in the Bohai Bay (Xu et al., 2000) does

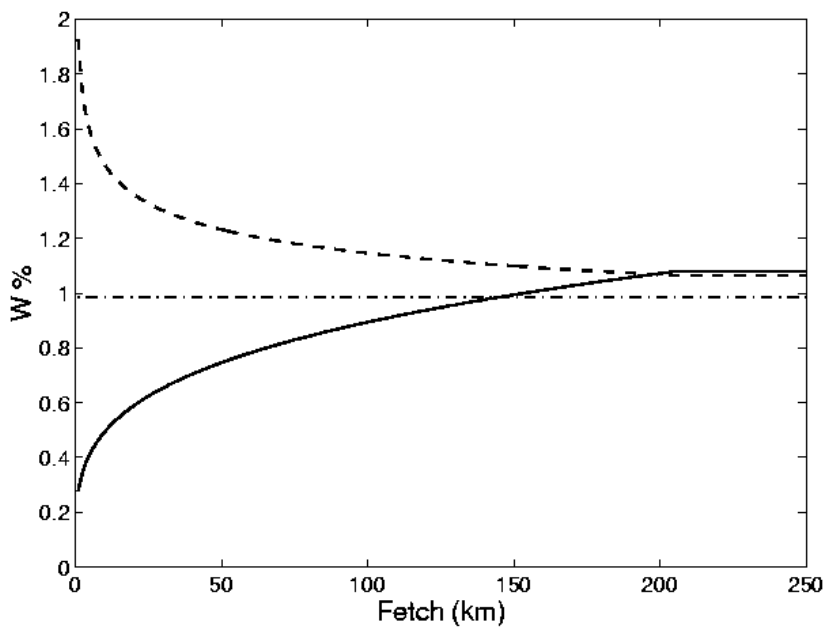

Fig. 1. Predictions of the two models described in the text for the whitecap fraction variation versus the fetch length for a wind speed of $10 \mathrm{~m} / \mathrm{s}$. The thick line represents the expression reported in Eq. (15) and the dashed line is the model proposed by Wu (1988) reported in Eq. (5). For comparison, the classical model (Eq. (2) in the text) by Monahan and O'Muircheartaigh (1980) is plotted with a dashed-dotted line.

not provide a whitecap percentage larger than 1 . For example, Xu et al. (2000) found about $1 \%$ of the sea surface is covered by whitecaps for a $60 \mathrm{~km}$ fetch and for a $10 \mathrm{~m} / \mathrm{s}$ wind speed. This is the reason why the model reported in Eq. (15) will be used in the present paper for the flux calculations (Sect. 3). The saturation of the wave spectrum occurs for typically $\xi \approx 20300$ (Hsu, 1986), with $\xi$ as the nondimensional fetch. In these conditions, the sea is fully developed. For a wind speed of $10 \mathrm{~m} / \mathrm{s}$, for example, fully developed conditions occur for fetch lengths larger than $200 \mathrm{~km}$. We can verify that this value corresponds to the constant portion of the curves reported in Fig. 1 and confirms that the two fetch-dependent models reported in Eq. (5) and Eq. (15) show reasonable agreement in infinite fetch conditions and also quite good agreement with the classical expression reported in Eq. (2).

\section{Variation in the aerosol generation flux with fetch}

Since the aerosol production is proportional to the whitecap fraction (Eq. 1), we can introduce the effect of the fetch in the marine aerosol generation flux derived by Monahan et al. (1986) by using the fetch-dependent $W$ as reported in Eq. (15). Since this paper focuses on the indirect sea surface production through bubble bursting processes, we used the aerosol source function proposed by Monahan et al. (1986), which is given by

$\frac{d E}{d r}=1.26 \cdot 10^{6} r^{-3} \cdot 10^{1.19 \exp \left(-B^{2}\right)}$

where $B=(0.38-\log r) / 0.650$ and $r$ (in $\mu \mathrm{m}$ ) is the radius in air of $80 \%$ relative humidity. 

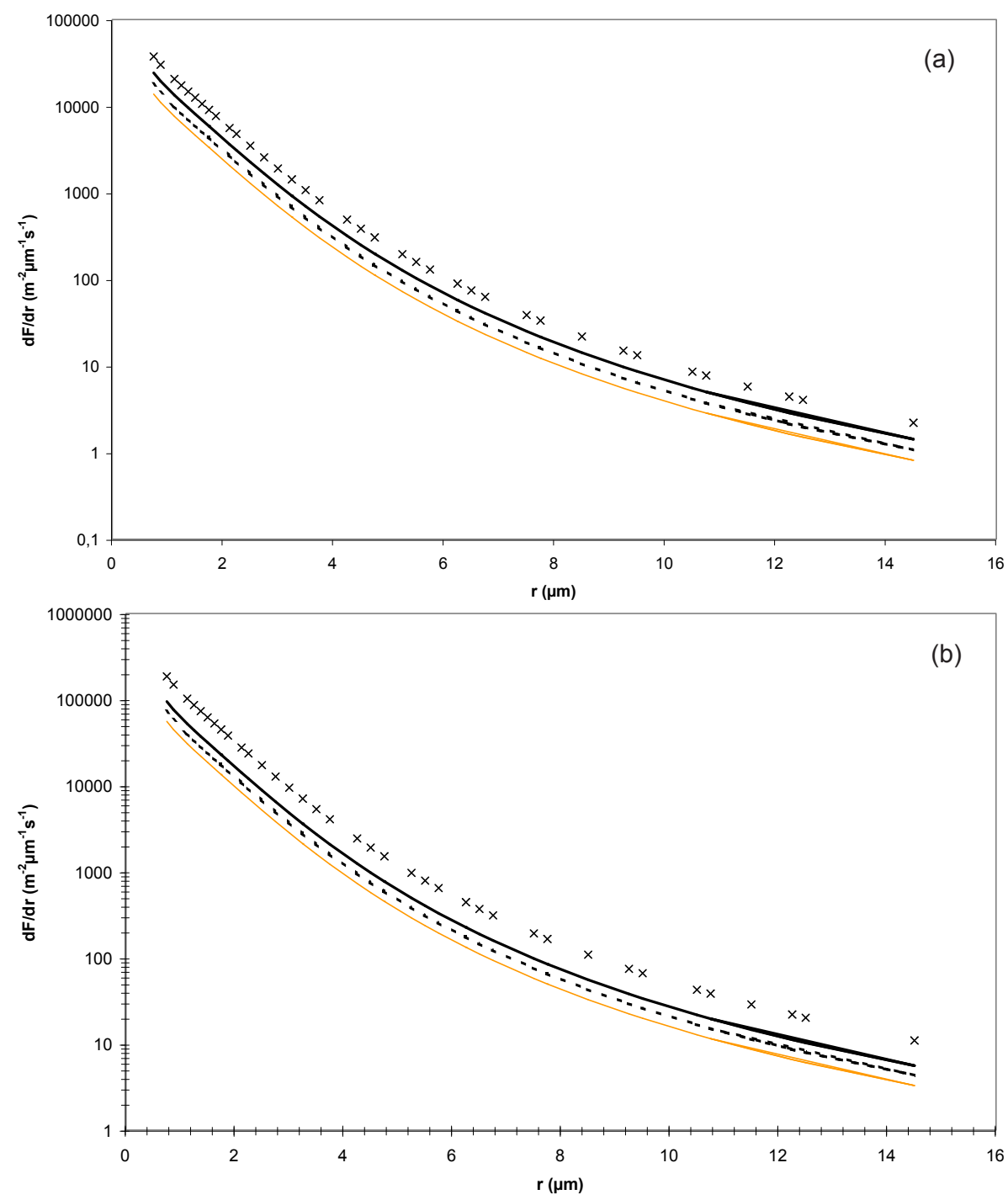

Fig. 2. (a) Generation fluxes derived from Eq. (1) and Eq. (17) using the fetch dependent model for the whitecap fraction reported in Eq. (15) for three fetch lengths and for a wind speed of $10 \mathrm{~m} / \mathrm{s}$. The thin curve represents a $3-\mathrm{km}$ fetch, the dashed line concerns a $10-\mathrm{km}$ fetch, and the black thick curve is the flux calculated for a 22-km fetch. The crosses represent the flux calculations using the classical whitecap model by Monahan and O'Muircheartaigh (1980). (b) Generation fluxes derived from Eq. (1) and Eq. (17) using the fetch dependent model for the whitecap fraction reported in Eq. (15) for three fetch lengths and for a wind speed of $16 \mathrm{~m} / \mathrm{s}$. The thin curve represents a 3-km fetch, the dashed line concerns a $10-\mathrm{km}$ fetch, and the black thick curve is the flux calculated for a 22-km fetch. The crosses represent the flux calculations using the classical whitecap model by Monahan and O' Muircheartaigh (1980).

Indeed, the whitecap productivity studies of Monahan and co-workers relate directly to the indirect sea surface production through bubble bursting processes. The enhancement of the particle concentration due to the direct production of spume drops is not taken into account by the whitecap fluxes reported here. Although Monahan et al. (1986) also proposed a tentative expression for this contribution, it is well recognized that it is not reliable (e.g. De Leeuw, 1993; Andreas et al., 1995). However, the latter review of the spray generation functions available in the literature by Andreas (1998) shows that the function of Monahan et al. (1986) is the best formulation for predicting the production rate of film and jet drops. The evolution of the aerosol generation fluxes using the fetch dependant whitecap fraction reported in Eq. (15) qualitatively confirms the variation in the experimental aerosol size distributions measured at different fetch lengths (Sect. 4). We have plotted in Figs. 2a and $2 \mathrm{~b}$ the generation fluxes calculated for two wind speeds of $10 \mathrm{~m} / \mathrm{s}$ and $16 \mathrm{~m} / \mathrm{s}$, respectively, using the whitecap fraction reported in Eq. (15). The wind speed values and the three fetches were chosen to be compared to our experimental data (Sect. 4), and the generation fluxes are calculated for three fetch lengths. For comparison, we have plotted on the same figure for each wind speed the classical expression for the whitecap fraction proposed by Monahan and O'Muircheartaigh (1980), as reported in Eq. (2). We can see that the flux estimated us- 


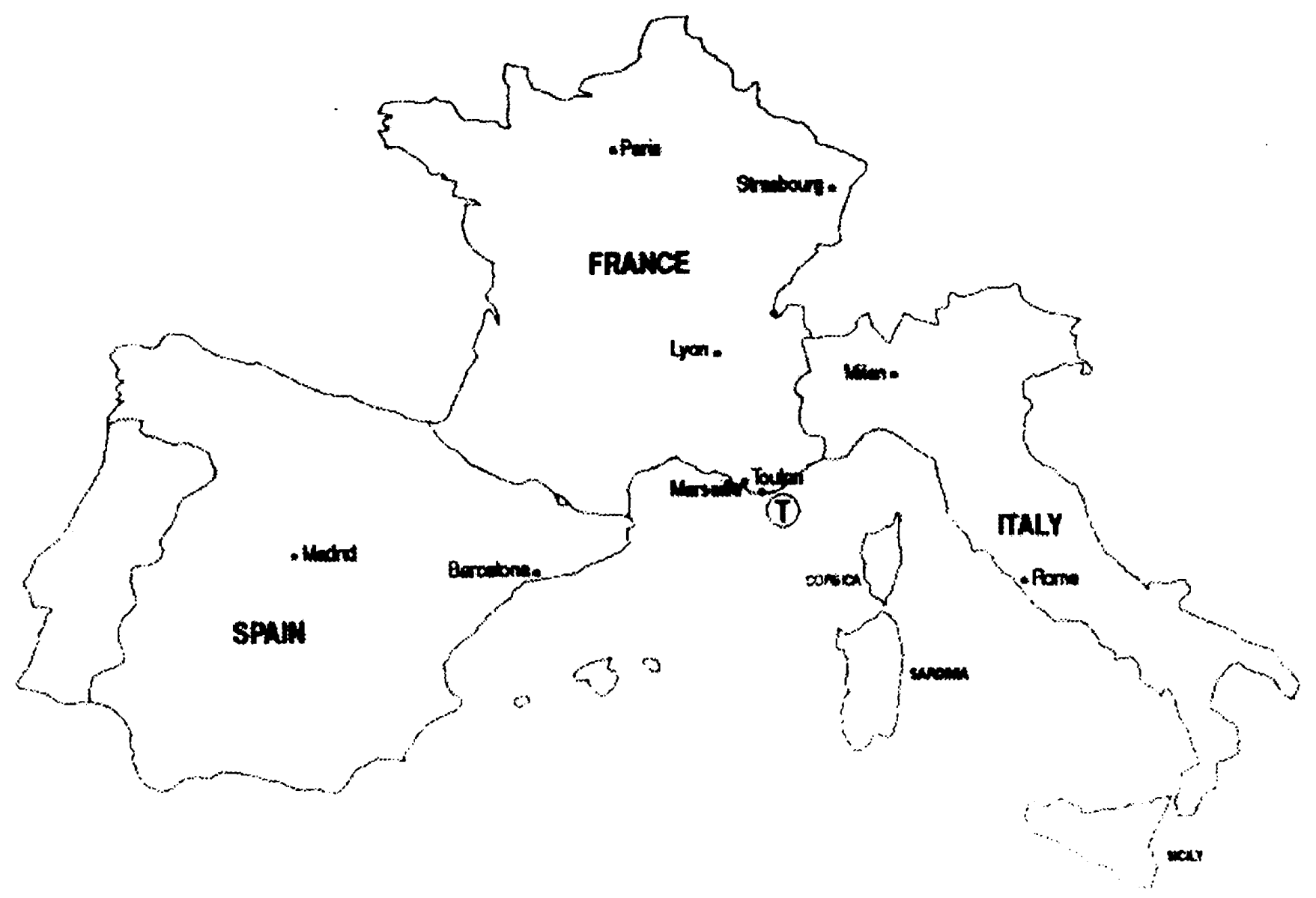

Fig. 3. Experimental site on the French MediterraneanCcoast. The site of experiments is marked by the symbol $T$.

ing the Monahan and O'Muircheartaigh expression is always larger than that derived from the whitecap fraction reported in Eq. (15). In addition, we note that the flux calculated using Eq. (15) increases with fetch. For $10 \mathrm{~m} / \mathrm{s}$, we note a relative difference of $40 \%$ between the generation flux estimated at 3 and $22 \mathrm{~km}$. The difference between the flux at $3 \mathrm{~km}$ and the flux calculated with the Monahan and O'Muircheartaigh expression is then around $60 \%$. These differences are enhanced for higher wind speeds $(16 \mathrm{~m} / \mathrm{s})$, as shown in Fig. $2 \mathrm{~b}$, where we observe a relative difference of about $45 \%$ between the flux estimated at 3 and $22 \mathrm{~km}$, while the relative difference between the flux calculated using Eq. (14) and the flux calculated using the Monahan and O'Muircheartaigh relation is about $70 \%$. This suggests that the formulation reported in Eq. (2) is adapted to remote oceans.

\section{Experimental aerosol size distributions recorded at various fetches}

\subsection{Field site and sample strategy}

The present paper deals with aerosol concentrations measured near the sea surface on the French Mediterranean Coast (Fig. 3), in the Toulon Bay (Fig. 4), using the French

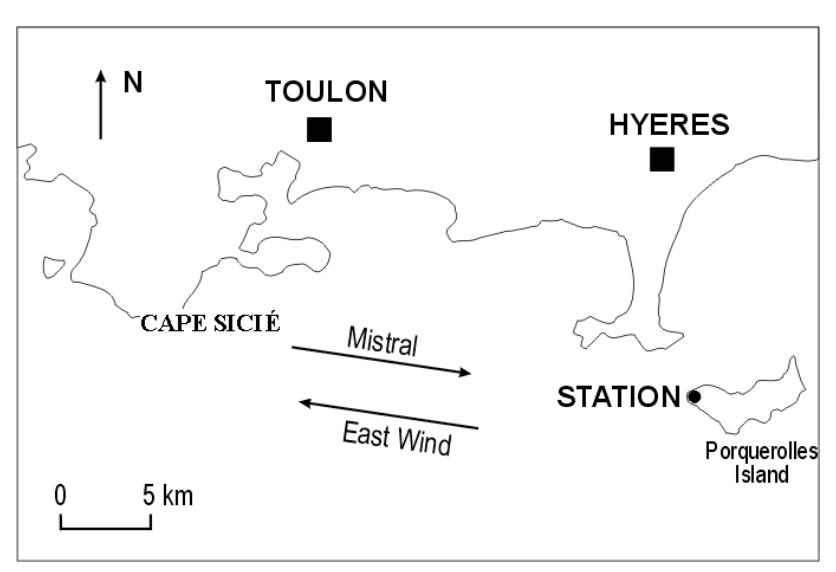

Fig. 4. Detailed view of the study area with the direction of dominant winds.

Navy ship Albacore, as described by Piazzola and Despiau (1997a). Size distributions between 0.1 and $47 \mu \mathrm{m}$ in diameter were obtained using three optical particle counters mounted at the back of the ship, i.e. a Royco 5250-A, an active scattering spectrometer probe (Particle Measuring Systems, ASASP-X) and a classical scattering spectrometer 
probe (Particle Measuring Systems, CSASP-100 HV). These probes were located at more than $40 \mathrm{~m}$ away from the bridge. The data accumulation period was $4 \mathrm{~min}$, and the data were stored as the average over a 15 min interval. To facilitate the analysis, the measured distributions were interpolated using polynomial approximations. Prior to the experiments, the probes had been calibrated with particles of known sizes. Software based on a wind tunnel study shows that a $30 \mathrm{~m}$ away from the bridge, accurate measurements can be made if we assume that the influence of the instrumentation structure is negligible. To reduce the perturbation of the wave flow during the sampling period, the ship was kept stationary with the stern constantly facing into the wind. This was achieved by using the two lateral stem motors while the central propeller was stopped.

The study area is subject to two dominant wind regimes: east-southeast or northwest winds (Fig. 4). To study the short-fetch conditions, this paper focuses on data recorded during northwest winds, called "Mistral". In Fig. 5, examples of back trajectory starting at $950 \mathrm{hPa}$ for a high wind speed period of Mistral in the study area are reported. Air sampled between Cape Sicie and the Porquerolles Island has spent the last 2 days over the continent, but we note that it can be originally transported from the Atlantic as well as from Eastern Europe (Piazzola and Despiau, 1997b). The fetch over water is then $25 \mathrm{~km}$ and is classified as a short fetch in deep-water conditions. For such wind directions and steady wind speeds, the aerosol concentrations were systematically sampled at three different locations along the fetch $(3,10$ and $22 \mathrm{~km}$ ). The meteorological conditions were monitored on the ship and at Porquerolles Island with standard sensors providing wind speed and direction, air and sea surface temperature, and relative humidity.

The data set selected in the present study was chosen to have a steady-state wave field and meteorological parameters. In particular, the time lag required to reach sea state equilibrium, i.e. the fetch-limited conditions, as reported in Eq. (11), has been respected for the sampling strategy, i.e. that means that the measurements of the aerosol distributions reported in the paper took place a few hours after the beginning of a northwest wind situation.

\subsection{Results}

In Figs. $6 \mathrm{a}$ and $6 \mathrm{~b}$ the aerosol size distributions measured at a $1 \mathrm{~m}$ height above the sea surface at three locations over the sea $(3,10$ and $22 \mathrm{~km})$ along the short-fetch Cape SiciePorquerolles using the Albacore during a northwest wind of $10 \mathrm{~m} / \mathrm{s}$ and $16 \mathrm{~m} / \mathrm{s}$, respectively, are reported. We can observe substantial variations in the aerosol size distribution with increasing fetch. In particular, the particle size distributions reported in Fig. 6a show a decrease in the concentration of submicrometer particles at larger fetch, whereas over about 0.5 $\mu \mathrm{m}$ in size, the concentrations increase with increasing fetch length. This shows that for very short fetches, the aerosol concentrations have probably not reached their equilibrium values.
The observed behaviour of the aerosol size distribution with increasing fetch is directly related to the mixed origin of the coastal aerosol. Chemical characterization of aerosols simultaneously measured on land and on Porquerolles Island during continental northwest wind periods (Despiau et al., 1996) showed that the $25 \mathrm{~km}$ fetch acts as a significant sink for continental coarse particles (largely constituted of Silicates), as well as a significant source for marine coarse particles (chlorides). In addition, on the basis of an extensive series of measurements on Porquerolles Island, Piazzola and Despiau (1997b) concluded that aerosols constituting the accumulation mode (particles in the 0.1-0.3 $\mu \mathrm{m}$ size band) are largely of continental origin during northwest wind episodes, whereas the particles smaller than $0.05 \mu \mathrm{m}$ and those larger than $0.5 \mu \mathrm{m}$ (for relative humidity of $80 \%$ ) were showed to be essentially of marine origin. This was recently confirmed by chemical analysis using ionic chromatography of particles collected with a low pressure cascade impactor during the FETCH campaign in the Gulf du Lion (Hauser, 2000) by Sellegri et al. (2001). Measurements made in the case of winds of continental origin, at a distance from the coast of less than $100 \mathrm{~km}$, showed that the accumulation mode is primarily constituted of Nitrate, Ammonium and nss sulfates, which indicates an anthropogenic influence. Thus, as the fetch increases, the removal of continental aerosols from the atmosphere by turbulent deposition and gravitational sedimentation is probably not balanced by an equivalent production of new particles. Therefore, explains the decrease in the sub micron aerosols with increasing fetch, as observed in Fig. 6.

As outlined above, for a northwest wind in the size range considered in the present paper, the production of aerosols at the air-sea interface primarily concerns particles larger than about $0.5 \mu \mathrm{m}$ at $80 \%$ relative humidity (Piazzola and Despiau, 1997b). As shown in Fig. 6a, the part of the spectrum that corresponds to these sea-salt particles typically shows larger concentrations when the fetch length increases, suggesting the marine aerosols to be in large numbers for large fetches. Thus, a balance equation between production and removal processes does not apply to shorter fetches. In particular, Fig. 6a shows that the behaviour of the aerosol distribution as an air mass that leaves the land and travels over the sea is similar to the behaviour of the aerosol distribution when the continental air mass is replaced by a marine one, as noted by Vignati et al. (1999). However, the detail of the variations in the sea-salt and continental contributions between 3 and $22 \mathrm{~km}$ fetch shows that the decrease in the submicron particles is less noticable when the aerosol size increases. This is probably due to the enhancement of the marine contribution with increasing particle size. These new marine submicron particles probably tend to counterbalance the loss of the continental ones induced by removal processes.

In Fig. 7, a close-up of on Fig. 6 for the particles larger than $0.5 \mu \mathrm{m}$ is reported. For the supermicrometer particles, the increase in concentrations with increasing fetch is more noticable for larger particle sizes. Continental northwest winds predominantly carry submicrometer particles, re- 


\begin{tabular}{|c|c|}
\hline TRAJECTOIRE & DU 920412 A 16 H TU AU 920416 A 16 H TU \\
\hline ECMWF & $\begin{array}{ll}\text { POINT } & \text { AIX EN PROVENCE } 01 \\
\text { LATITUDE } & 43 \mathrm{deg} 2 \mathrm{~min} \mathrm{~N}\end{array}$ \\
\hline FINISSANTE & $\begin{array}{l}\text { LONGITUDE } 6 \text { deg } 10 \mathrm{~min} \mathrm{E} \\
\text { ALTITUDE } \\
950 \mathrm{hPA}\end{array}$ \\
\hline
\end{tabular}

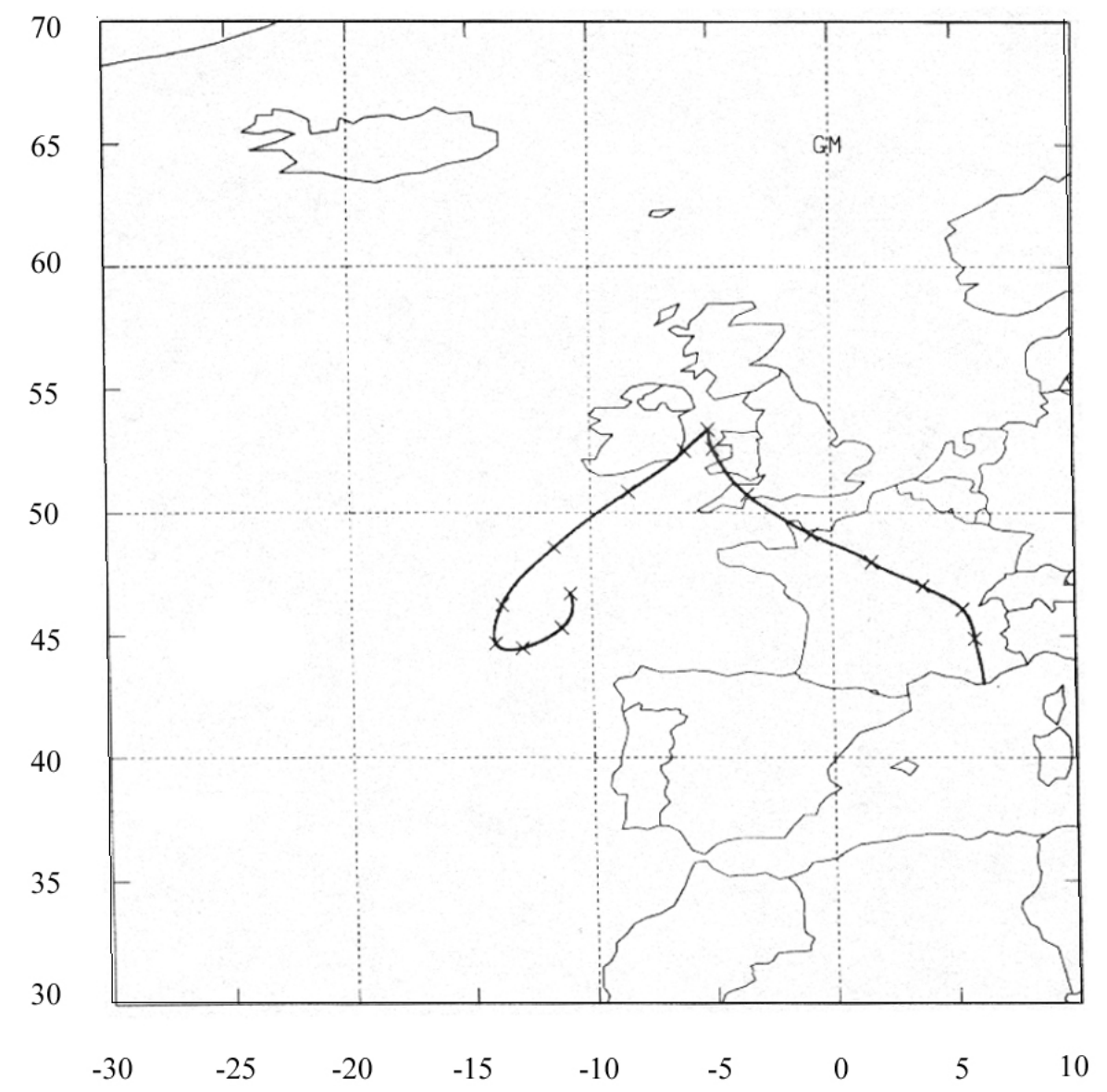

Fig. 5. Four day back trajectories, starting at $950 \mathrm{hPa}$ for a local northwest wind. The last point of the calculated trajectory line is the Mediterranean Sea. Crosses indicate $6 \mathrm{~h}$ intervals. sulting in a strongly decreasing slope for the aerosol spectrum over $1 \mu \mathrm{m}$ in size, which is well described by a Junge function with an exponent smaller than -3 . This implies that the marine contribution generated over the fetch is more dominant as the particle size increases. This confirms that the whitecap fraction, and hence, the aerosol generation processes depend on the sea state development. In particular, the distributions reported in Fig. 7 show substantial variations for larger aerosols $(r>4 \mu \mathrm{m})$. The net enhancement of the larger particle concentration is probably related to the development of the sea state. Indeed, the wave height is expected to increase with increasing fetch, and the larger aerosols, as the spume drops, are primarily created from the surface tearing at the wave crests. For larger fetches, the wave field has absorbed more energy from the wind than from smaller fetches with probably more of a chance to induce a substantial enhancement of the instantaneous active whitecaps (Monahan and Woolf, 1989), which largely contribute the mechanical extraction of spume drops by the wind.

\section{Discussion}

The extrapolation of the Monahan et al. (1986) sea spray generation function to fetch-limited conditions shows that between a 3 and $22 \mathrm{~km}$ fetch, fetch effects can make more than a factor of 3 difference in spray generation. The wave conditions can be theoretically fetch-limited for at least two hundred kilometers if the wind is strong enough. For example, the upper limit of the fetch in order for the wave conditions to be fetch-limited is $200 \mathrm{~km}$ for a wind speed of about 10 $\mathrm{m} / \mathrm{s}$ (see Hsu, 1986). Thus, one can expect a larger factor by comparing coastal data with aerosol spectra recorded in open oceans. The fetch effect is then of great importance to the marine aerosol generation. In addition, the experimental aerosol size distributions measured for various fetch lengths (Fig. 6) show that this factor is probably underestimated and it could increase up to the factor of 5 as the aerosol size increases. For the supermicrometer particles, the enhancement of concentrations with increasing fetch is more important as the aerosol size increases. This is particularly noticeable for 

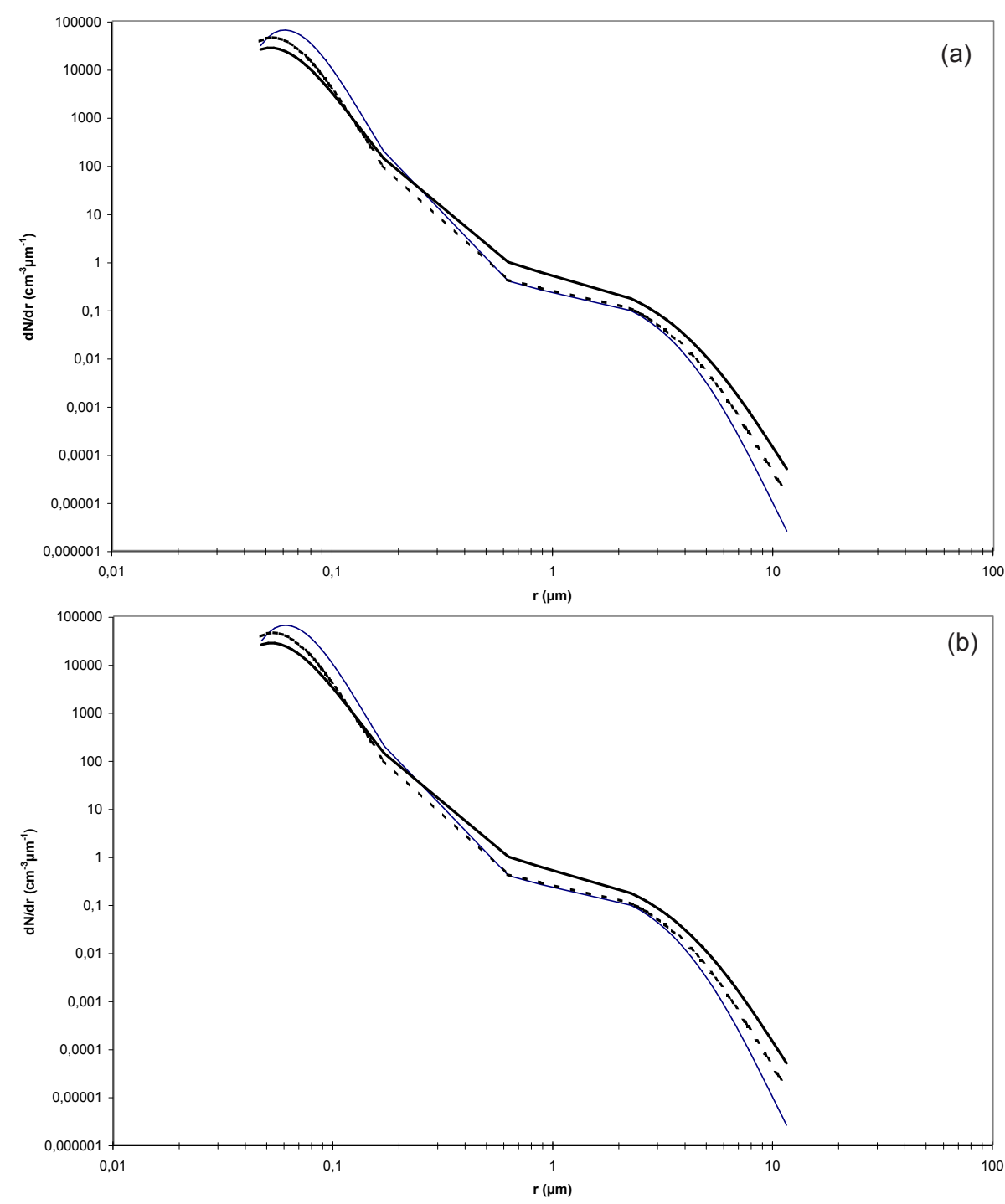

Fig. 6. (a) Aerosol size distributions measured at three different fetches during a northwest wind of $10 \mathrm{~m} / \mathrm{s}$. The thin curve was recorded at a $3-\mathrm{km}$ fetch, the dashed line was recorded at a $10-\mathrm{km}$ fetch and the thick line was recorded at a $22 \mathrm{~km}$. The distributions were normalized to $80 \%$ relative humidity. (b) Aerosol size distributions were measured at two fetch lengths during a northwest wind of $16 \mathrm{~m} / \mathrm{s}$, the dashed line measured at a $10-\mathrm{km}$ fetch and the thick line measured at a $22 \mathrm{~km}$. The distributions were normalized to $80 \%$ relative humidity (see Van Eijk and De Leeuw, 1992).

high wind speed periods (Fig. 6b). The larger sizes of the aerosol spectrum largely consist of spume drops mechanically extracted by the wind at the wave crest. It is then clear that our spray function should consider the spume drop production, which is important in fetch-limited conditions. In particular, as the fetch increases, the enhancement of the energy absorbed by the wave from the wind probably induces a substantial enhancement of the instantaneous active whitecaps. This should largely contribute to the mechanical extraction of spume drops by the wind. Since wave energy is directly dependent on the wave height, it is probable that the larger aerosols, as the spume drops, are well correlated to the significant wave height. A fetch-dependent formulation for the spume drop production probably requires the necessity of the introduction of the wave height (or wave steepness) in the whitecap model. However, there are still too many uncertainties in the spume production models, which are largely inherent to the spume drop concentration measurement with current technology, to be able to experimentally validate such models.

Although the model for the whitecap fraction presented in Eq. (15) suggests that the wave evolution counterbalances the decrease in the wind stress, it uses a simple wave estimate, as reported in Eq. (12) and Eq. (13), which is possible only if the geometry of the water body is relatively simple and the wave conditions are fetch-limited, i.e. steady-state. This represents an idealized situation, particularly in the coastal zone, where the wave field is often found in an unsteady condition (Lafon et al., 2000). The variation in the whitecap fraction in a developing wave field is probably slightly dif- 

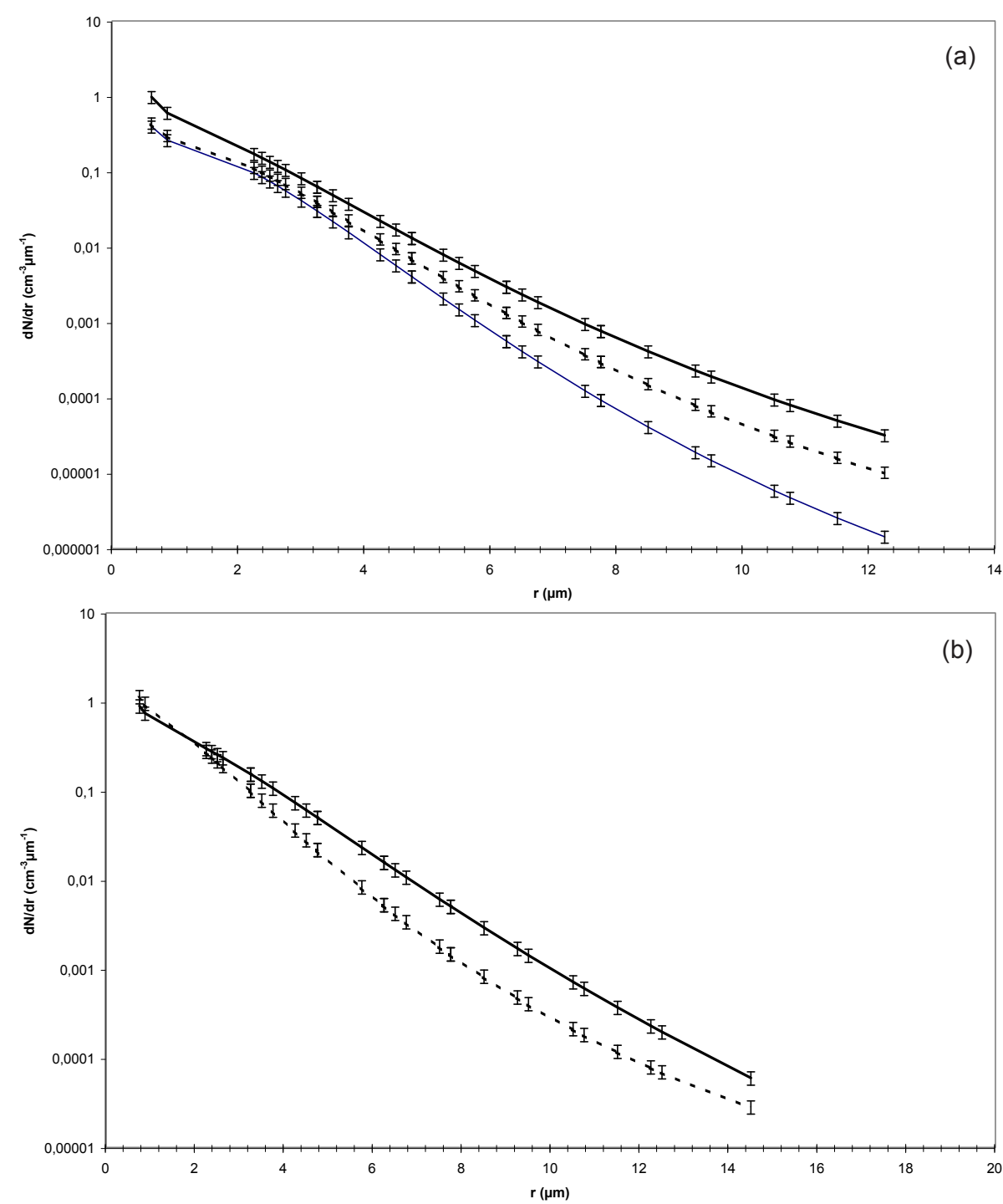

Fig. 7. (a) Close-up on Fig. 6a for particle sizes larger than $0.5 \mu \mathrm{m}$. (b) Close-up on Fig. $6 \mathrm{~b}$ for particle sizes larger than $0.5 \mu \mathrm{m}$.

ferent. In particular, although this paper considers that the wind stress decreases with increasing fetch, as suggested by the majority of the air-sea interaction studies, the dependence of the wind stress on the sea state is not well-known, particularly for the younger waves. Previous studies on the air-sea interaction processes suggest that the wind stress increases with the wave age for wave a age smaller than 10 , whereas it decreases with wave age for wave a age larger than 10 (Donelan et al., 1993; Nordeng, 1991). Smallest wave age can probably be encountered for strong atmospheric instabilities, which occur for land winds, even though Donelan et al. (1993) suggest that a wave age smaller than 10 corresponds to laboratory conditions. Obviously, future work should focus on the aerosol generation processes for younger wave fields.

Finally, it should be noted that the sea spray function is dependent on the model used for the wind stress, as well as the roughness length (Eq. 9). Slight changes in the whitecap model can be found for different roughness length expressions, as those derived by Johnson et al. (1998) or Hsu (1986). A good agreement is found in the literature about the formulation of Donelan et al. (1993), as shown by Hsu (1994). However, the present results should be extended to various atmospheric stability conditions and unsteady sea states.

\section{Conclusion}

This paper presented an extrapolation of the Monahan et al. (1986) spray generation flux calculations to fetch-limited conditions using a fetch dependent model for the whitecap fraction deduced from the work of Toba and Koga (1986). The results show that there is a significant sensitivity of spray production to fetch, with spray production decreasing at small fetches. This is confirmed by the experimental study of the variations in the aerosol size distribution with 
fetch, which shows the decrease in the concentration of submicrometer particles at larger fetch, Whereas for particles larger than about $0.5 \mu \mathrm{m}$, the concentrations increase with increasing fetch. This specific behavior of the particle size distributions is related to the influence of the fetch on marine aerosol generation and subsequent particle dispersion.

The present study is limited to steady-state conditions for the wave field. To improve our knowledge about aerosol generation and transport in coastal areas, investigations are needed on whitecap fraction and marine aerosol production in young developing wave fields. Work is currently in progress concerning unsteady wave fields and their relation with marine aerosol generation processes. In addition, the experimental size distributions reported in the present paper show that future work should focus on the study of the specific contribution of the spume drop production to the aerosol spectrum in fetch-limited conditions. In particular, a future development of the present work is the extension of the fetchdependent source function to the spume drop production.

Acknowledgements. The authors wish to thank G. De Leeuw for his helpful comments on an early draft of this paper and the two anonymous reviewers for a useful critique. This work was supported by the French Ministry of Research.

The Editor in Chief thanks a referee for his help in evaluating this paper.

\section{References}

Andreae, M. O.: Climate effects of changing atmospheric aerosol levels, in: World survey of climatology, Vol. 16, Future climate of the world, (Ed) Henderson-Sellers, A., 341-392, 1995.

Andreas, E. L.: A new sea spray generation function for wind speeds up to $32 \mathrm{~ms}^{-1}$, J. Phys. Oceanogr., 28, 2175-2184, 1998.

Andreas, E. L., Edson, J. B., Monahan, E. C., Rouault, M. P., and Smith, S. D.: The spray contribution to net evaporation from the sea: a review of recent progress, Boundary-layer Meteorology, 72, 3-52, 1995.

Blanchard, D. C.: The electrification of the atmosphere by particles from bubbles in the sea, Prog. Oceanogr., 1, 71-202, 1963.

Carter, D. J. T.: Prediction of wave height and period for a constant wind velocity using the Jonswap results, Ocean Engineering, 9, 1, 17-33, 1982.

Charlson, R. J., Schawrtz, S. E., Hales, J. M., Cess, R. D., Coakley, Jr., J. A., Hansen, J. E., and Hoffmann, D. J.: Climate forcing by anthropogenic aerosols, Science, 255, 423-430, 1992.

De Leeuw, G.: Aerosols near the air-sea interface, Trends in Geophys. Res., 2, 55-70, 1993.

Despiau, S., Cougnenc, S., and Resch, F. J.: Concentrations and size distributions of aerosol particles in coastal zones, J. Aerosol Sci., 27, 3, 403-415, 1996.

Donelan, M. A., Hamilton, J., and Hui, W. H.: Directional spectra of wind-generated waves, Phil. Trans. R. Soc. Lond., A 315, 509$562,1985$.

Donelan, M. A., Dobson, F. W., Smith, S. D., and Anderson, R. J.: On the dependence of sea surface roughness on wave development, J. Phys. Oceanogr., 23, 2143-2149, 1993.

Geernaert, G. L.: The theory and modeling of wind stress with applications to air-sea interaction and remote sensing, Reviews in Aquatic Sciences, 2, 1, 125-149, 1990.
Hasselman, K., Barnett, T. P., Bouws, E., Carlson, H., Cartwright, D. E., Enke, K., Ewing, J. A., Gienapp, H., Hasselman, D. E., Krusemann, P., Meerburg, A., Müller, P., Olbers, D. J., Richters, K., Sell, W., and Walden, H.: Measurements of the wind wave growth and swell decay during the Joint North Sea Wave Project (JONSWAP), Deutsch. Hydr. Z., Suppl. A, 8, 95, 1973.

Hauser, D., Dupuis, H., Durrieu, X., De Madron, C., Estournel, C., Flamant J., Pelon, P., and Queffeulou, P.: La Campagne FETCH: Une expérience l'étude des échanges océan/atmosphère dans les conditions côtières du Golfe du Lion, La Météorologie (in press), 2000.

Hsu, S. A.: A dynamic roughness equation and its application to wind stress determination at the air-sea interface, J. Phys. Oceanogr., 4, 116-120, 1974.

Hsu, S. A.: A mechanism for the increase of wind stress (drag) coefficient with wind speed over water surfaces: A parametric model, J. Phys. Oceanogr., 16, 144-150, 1986.

Hsu, S. A.: A verification of two shear velocity equations for the wind-wave interaction in a lake environment, Boundary-Layer Meteorology, 71, 205-209, 1994.

Huang, N. E., Bliven, L. F., Long, S. R., and De Leonibus, P. S.: A study of the relationship among wind speed, sea state, and the drag coefficient for a developing wave field, J. Geophys. Res., 91, 7733-7742, 1986.

Johnson, H. K., Hojstrup, J., Vested, H. J., and Larsen, S. E.: On the dependence of sea surface roughness on wind waves, J. Phys. Oceanogr., 28, 1702-1716, 1998.

Kahma, K. K.: A study of the growth of the wave spectrum with fetch, J. Phys. Oceanogr., 11, 1503-1515, 1981.

Komen, G. J., Hasselmann, S., and Hasselmann, K.: On the existence of a fully developed wind-sea spectrum, J. Phys. Oceanogr., 14, 1271-1285, 1984.

Lafon, C., Piazzola, J., Forget, P., and Despiau, S.: Sea surface state characteristics in coastal zone and its influence on the aerosol generation, Geophys. Res. Abstr., 25th General Assembly, section OA2-02, ISSN, 2, 1029-7006, 2000.

Large, W. G. and Pond, S.: Sensible and latent heat flux measurements over the ocean, J. Phys. Oceanogr, 12, 464-482, 1982.

Maat, N., Kraan, C., and Oost, W. A.: The roughness of wind waves, Boundary-Layer Meteorology, 54, 89-103, 1991.

Mitsuyasu, H., Tasai, F., Suhara, T., Mizuno, S., Ohkusu, M., Honda, T., and Rikiishi K.: Observation of the power spectrum of ocean waves using a cloverleaf buoy, J. Phys. Oceanogr., 10, 286-296, 1980.

Monahan, E. C.: Oceanic whitecaps, J. Phys. Oceanogr., 1, 139144, 1971.

Monahan, E. C. and O'Muircheartaigh, I.: Optimal power-law description of oceanic whitecap coverage dependence on wind speed, J. Phys. Oceanogr., 10, 2094-2099, 1980.

Monahan, E. C., Fairall, C. W., Davidson, K. L., and Boyle, P. J.: Observed interrelation between $10 \mathrm{~m}$ winds, ocean whitecaps and marine aerosols, Q. J. R. Meteorol. Soc., 109, 375-392, 1983.

Monahan, E. C. and Monahan, C. F.: The influence of the fetch on whitecap coverage as deduced from the Alte Weser lightstation observer's log, in: Oceanic Whitecaps, (Eds) Monahan, E. C. and MacNiocaill, G., Reidel, Hingham, Mass., 275-277, 1986.

Monahan, E. C., Spiel, D. E., and Davidson, K. L.: A model of marine aerosol generation via whitecaps and wave disruption, in: Oceanic Whitecaps, (Eds) Monahan E. C. and MacNiocaill G., Reidel, Hingham, Mass., 167-174, 1986.

Monahan, E. C.: Whitecap coverage as a remotely monitorable indication of the rate of bubble injection into the oceanic mixed layer, 
(Ed) Kerman, Sea surface sound, by Kluwer Academic Publishers, 85-96, 1988.

Monahan, E. C. and Woolf, D. K.: Comments on "Variations of whitecap coverage with wind stress and water temperature", J. Phys. Oceanography, 19, 706-709, 1989.

Nordeng, T. E.: On the wave age dependant drag coefficient and roughness length at sea, J. Geophys. Res., 96, C4, 7167-7174, 1991.

Piazzola, J. and Despiau, S.: Vertical distribution of aerosol particles near the air-sea interface in coastal zone, J. Aerosol Science, 28, 8, 1579-1599, 1997a.

Piazzola, J. and Despiau, S.: Contribution of marine aerosols in the particle size distributions observed in Mediterranean coastal zone, Atmospheric Environment, 31, 18, 2991-3009, 1997b.

Resch, F. and Afeti, G. M.: Submicron film drop production by bubbles in sea water. J. Geophys. Res., 97, C3, 3679-3683, 1992.

Sellegri, K., Despiau, S., and Gourdeau J.: Chemical composition of marine aerosol in a Mediterranean coastal zone during the FETCH experiment, J. Geophys. Res., in press, 2001.
Toba, Y. and Koga, M.: A parameter describing overall conditions of wave breaking, whitecapping, sea-spray production and wind stress, in: Oceanic Whitecaps, (Eds) Monahan E. C. and MacNiocaill G., Reidel, D., Hingham, Mass., 37-47, 1986.

Van Eijk, A. M. J. and De Leeuw, G.: Modeling aerosol particle size distributions over the North Sea, J. Geophys. Res., 97, C9, 14417-14 429, 1992.

Vignati, E., De Leeuw, G., Schulz, M., and Plate, E.: Characterization of aerosols at a coastal site near Vindeby (Denmark), J. Geophys. Res., 104, C2, 3277-3287, 1999.

Vickers, D. and Mahrt, L.: Fetch limited drag coefficients, Boundary-layer Meteorology, 85, 53-79, 1997.

Wu, J.: Oceanic Whitecaps and sea state, J. Phys. Oceanography, 9, 1064-1068, 1979.

$\mathrm{Wu}, \mathrm{J} .:$ Variations of whitecap coverage with wind stress and water temperature, J. Phys. Oceanography, 18, 1448-1453, 1988.

$\mathrm{Xu}, \mathrm{D}$., Liu, X., and Yu, D.: Probability of wave breaking and whitecap coverage in fetch-limited sea, J. Geophys. Res., 105, C6, 14 253-14 259, 2000. 